\title{
recA and gInA sequences separate the Bacteroides fragilis population into two genetic divisions associated with the antibiotic resistance genotypes cepA and cfiA
}

\author{
MICHAELA GUTACKER, CLAUDIO VALSANGIACOMO, MARCO V. BERNASCONI and \\ JEAN-CLAUDE PIFFARETTI
}

Istituto Cantonale Batteriosierologico, Via Giuseppe Buffi 6, CH-6904 Lugano, Switzerland

\begin{abstract}
The sequences of part of the glutamine synthetase-encoding gene $(g \ln A)$ and of the RecA-encoding gene $(\operatorname{rec} A)$ were determined and aligned for 45 Bacteroides fragilis isolates from different clinical and geographical origin. The patterns of sequence divergence of $g \ln A$ and $\operatorname{rec} A$ were very similar. The sequences of a 303-bp fraction of $\operatorname{rec} A$ showed 45 nucleotide substitutions, 40 of which allowed the separation of $B$. fragilis into two major divisions, which were not found when the deduced amino acid sequences were considered. The 687-bp sequences analysed for the $\operatorname{gln} A$ gene showed 112 nucleotide substitutions, 96 of which separated the population into the same two divisions as those described for $\operatorname{rec} A$. In this case, the deduced amino acid sequences showed this subdivision as well: three of the six observed amino acid substitutions were division-specific. Within the two divisions, both genes presented a high degree of sequence conservation. Each $B$. fragilis division was associated with the presence of a different antibiotic resistance gene: $c e p A$ encoding a serine- $\beta$-lactamase (division I) and cfi $A$ encoding a metallo- $\beta$-lactamase (division II). No particular clusters associated with geographical or clinical origin, or with the production of an enterotoxin were observed. Sequencing of the $c f i A$ gene allowed identification of two different alleles in division II. However, no association of these different $c f i A$ alleles with the expression of imipenem resistance was observed. In conclusion, the phylogenetic patterns observed by sequencing $\operatorname{rec} A$ and $\operatorname{gln} A$ are in agreement with those obtained previously by MLEE (multilocus enzyme electrophoresis). Thus, it appears that the evolution of $\operatorname{rec} A$ and $g \ln A$ genes is similar to that of the whole chromosome of $B$. fragilis. Horizontal gene transfer between divisions I and II seems to be low, at best. However, the results of the present study could not clarify definitively whether divisions I and II should be considered as two different $B$. fragilis genospecies.
\end{abstract}

\section{Introduction}

Bacteroides fragilis is a gram-negative, obligately anaerobic, opportunist pathogen present in the normal gut flora. Occasionally, some strains produce an enterotoxin [1,2]. Studies with multilocus enzyme electrophoresis (MLEE) [3] and other molecular techniques - particularly 16S rRNA sequencing [4] and DNA-DNA hybridisation [5] - have shown the separation of the population into two groups presenting

Received 20 June 2001; accepted 6 July 2001.

Corresponding author: Professor J-C. Piffaretti (e-mail: jeanclaude.piffaretti@ti.ch). an extensive genetic distance one from the other (divisions I and II). Division I was characterised by the frequent presence of the cep $A$ gene (encoding a serine- $\beta$-lactamase of Ambler's class A) and the absence of the $c f i A$ gene (encoding a metallo- $\beta$ lactamase of Ambler's class B). Division II was characterised by the presence of the cfiA gene, the absence of the cep $A$ gene and a higher genetic homogeneity. Three specific insertion sequence elements, IS1186, IS942 and IS4351, providing the promoter region for the $c f i A$ gene and leading to the expression of imipenem resistance, were shown to be strictly associated with this group [6, 7].

As MLEE may underestimate the real extent of 
nucleotide sequence differences, this study sequenced two different genetic markers, $\operatorname{rec} A$ and $g \ln A$, with the aim of obtaining a direct measure of nucleotide diversity among $B$. fragilis strains. Recently, DNA sequence typing has provided significant insights into the population structure and evolution of many bacteria [8-10]. To our knowledge, the present study is the first to apply sequencing of housekeeping genes to $B$. fragilis to obtain information on the structure and evolution of its population.

The recA gene encodes RecA, a protein which is ubiquitous in eubacteria, playing a crucial role in homologous recombination, DNA repair and SOS response [11]. Specifically, RecA binds stretches of single-stranded DNA, unwinds duplex DNA and finds regions of homology between chromosomes in homologous recombination. In this context RecA is required for synapses and strand transfer. Moreover, it is implicated in proteolysis of the repressor protein LexA and induces activity of more than 15 SOS response genes [11]. The protein RecA is substantially conserved across bacterial genera [12]. Previous studies based on a RecA amino acid sequence alignment [12] and on significant segment pair alignment [11] showed strong concordance with those derived from 16S rRNA sequences [13]. Furthermore, a study in Neisseria spp. focusing on the recA gene made it possible to obtain important information on the bacterial evolution and population structure [14]. Thus, RecA seems to be a good phylogenetic marker at several taxonomic levels within eubacteria, and the recA gene might also be a valuable phylogenetic marker for the identification of genetic subgroups within a defined species.

The second gene $(g \ln A)$, encoding glutamine synthetase (GS), has also been used in the past for phylogenetic studies comparing archaea to bacteria $[15,16]$. GS is an important enzyme involved in nitrogen metabolism and ammonia assimilation in many eukaryotes and prokaryotes. It is present in three distinct isoforms: GSI, GSII and GSIII. GSIII has been observed in only a few bacterial species, including $B$. fragilis. The $B$. fragilis GSIII enzyme is very different from the other GS enzymes (GSI and GSII): its coding region is $2187 \mathrm{bp}$ long (compared with the 1050-1410bp length of the other two isoforms) and it constitutes a hexamer, not a dodecamer holoenzyme [17]. However, all GS isoforms show at least four regions of amino acid homology [17]. Two of these regions (region II and III) were included in the sequence fragment analysed in the present study.

\section{Materials and methods}

\section{Bacterial strains}

A total of 45 B. fragilis strains originating from different countries, one Bacteroides ovatus, and one Bacteroides uniformis was chosen from the sample collection, which was previously investigated by MLEE [3]. This collection included human invasive and non-invasive (recovered from patients' stools) strains from different geographical regions (Switzerland, France, Norway, USA and Japan), strains producing enterotoxin, invasive isolates from animals and one reference strain (ATCC 25285) of B. fragilis (Table 1). Bacteria were grown, identified and stored as described previously [3]. B. ovatus and B. uniformis were used as outgroup strains in the rec $A$ analysis, whereas no outgroup sequences were available for the $\operatorname{gln} A$ gene.

\section{DNA extraction and PCR}

Bacterial suspensions $(50 \mu \mathrm{l})$ frozen in water were thawed and DNA was extracted with a commercial ion-exchange resin (InstaGene Matrix, BioRad Laboratories, Richmond, CA, USA) according to the manufacturer's instructions. PCR was performed with $10 \mu \mathrm{l}$ of the DNA extract, $0.5 \mu \mathrm{M}$ of each primer and 1 unit of Taq polymerase (Boehringer Mannheim, Germany) in a total reaction volume of $50 \mu \mathrm{l}$ (buffer provided by the manufacturer); the reaction mixtures were overlaid with paraffin oil (Merck, Darmstadt, Germany) to prevent evaporation during the amplification, which was performed in a DNA Thermo Cycler (Perkin-Elmer Applied Biosystems, Foster City, CA, USA).

Primers recA-1 (5'-GACACTGGCCATCCACG-3') and recA-2 (5'-GCAACTGGTTGATGAAGATACA-3'), amplifying a 367-bp fragment of the $r e c A$ gene, on the basis of the DNA sequence alignment of $B$. fragilis [18], Bacteroides tetaiotaomicron [19] and B. uniformis were designed (A. J. Cooper and N. B. Schoemaker, GenBank accession no. AF013606). Then 35 cycles of PCR were performed with these primers with the following thermal profile: $94^{\circ} \mathrm{C}$ for $60 \mathrm{~s}, 55^{\circ} \mathrm{C}$ for $60 \mathrm{~s}$, $72^{\circ} \mathrm{C}$ for $90 \mathrm{~s}$.

Primers $g \ln A-1$ (5'-AGGAATATTTTTTGGTTGACA$\left.3^{\prime}\right)$ and $g \ln A-2$ (5'-AACGATTTCCTGTGAATGC-3'), amplifying part of the glutamine synthetase encoding gene, on the alignment of the $g \ln A$ sequence of $B$. fragilis [17] and Butyrivibrio fibrisolvens were designed [20]. These primers amplified a 780-bp fragment of the $g \ln A$ gene in a PCR of 35 cycles, with the following thermal profile: $94^{\circ} \mathrm{C}$ for $60 \mathrm{~s}, 52^{\circ} \mathrm{C}$ for $60 \mathrm{~s}$, $72^{\circ} \mathrm{C}$ for $60 \mathrm{~s}$.

To ensure that negative PCR results obtained with $B$. ovatus and $B$. uniformis were not a consequence of mutations in the regions complementary to the primers $\operatorname{gln} A-1$ and $g \ln A-2$, a nested PCR was performed according to the protocol of Yamashita et al. [21].

A fragment of $353 \mathrm{bp}$ of the $c f i A$ gene was amplified with primers $c f i A-1$ and $c f i A-2$ as described previously [3]. 
Table 1. B. fragilis strains

\begin{tabular}{|c|c|c|c|c|c|}
\hline Isolate No. & MLEE ET* & Biological origin & Geographical origin & $\begin{array}{l}\text { Genetic } \\
\text { characteristics }\end{array}$ & Source or reference \\
\hline \multicolumn{6}{|l|}{ Division I } \\
\hline V15 2735 & 2 & Blood & Switzerland, Zürich & $\operatorname{cep} A$ & R. Zbinden \\
\hline D3251 & 3 & Blood, cat & Switzerland, Bern & серA & J. Nicolet \\
\hline GAI20273 & 5 & Blood & Japan, Gifu & серA & N. Kato \\
\hline F59D & 6 & Stool from patient 59 & Switzerland, Ticino & серA & $\mathrm{IBS}^{\dagger}$ \\
\hline 25458 & 9 & Blood & Norway, Bergen & $\operatorname{cep} A$ & T. Hofstad \\
\hline 47 & 10 & Appendicitis with abscess & Switzerland, Ticino & серA & IBS \\
\hline AIP638 & 11 & Unknown & France, Paris & серA & {$[6]$} \\
\hline 70 & 14 & Intestinal fistula & Switzerland, Ticino & $\operatorname{cep} A, b f t-1$ & IBS \\
\hline 1332 & 17 & Sigmoid pelvic abscess & France, Paris & $\operatorname{cep} A$ & M. Sebald \\
\hline 31959 & 18 & Blood & Norway, Bergen & серA & T. Hofstad \\
\hline 30285 & 19 & Blood & Norway, Bergen & серA & T. Hofstad \\
\hline F70B & 21 & Stool from patient 70 & Switzerland, Ticino & cep $A$, bft-1 & IBS \\
\hline F126A & 24 & Stool from patient 126 & Switzerland, Ticino & серA & IBS \\
\hline F126C & 25 & Stool from patient 126 & Switzerland, Ticino & серA & IBS \\
\hline F126E & 25 & Stool from patient 126 & Switzerland, Ticino & серA & IBS \\
\hline 126 & 26 & Femur wound abscess & Switzerland, Ticino & $\operatorname{cep} A$ & IBS \\
\hline 118 & 28 & $\begin{array}{l}\text { Wound abscess after } \\
\text { appendectomy }\end{array}$ & Switzerland, Ticino & серA & IBS \\
\hline F118A & 29 & Stool from patient 118 & Switzerland, Ticino & серA & IBS \\
\hline 134 & 32 & Unknown & Switzerland, Ticino & cep $A$, bft-1 & IBS \\
\hline 136 & 36 & $\begin{array}{l}\text { Stool from patient with } \\
\text { Crohn's disease }\end{array}$ & France, Paris & серA, bft-2 & M. Sebald \\
\hline L362 & 45 & Blood & Switzerland, Vaud & серA & J. Bille \\
\hline VO8 12993 & 50 & Blood & Switzerland, Zürich & серA & R. Zbinden \\
\hline 93 & 55 & Blood, patient 80 & Switzerland, Ticino & серA & IBS \\
\hline 1301 & 56 & Bone infection & France, Paris & серA & M. Sebald \\
\hline GAI96448 & 58 & Stool & Japan, Gifu & серA, bft-1 & N. Kato \\
\hline L754 & 60 & Blood & Switzerland, Vaud & серA & J. Bille \\
\hline 1237 & 64 & Blood & France, Paris & серA & M. Sebald \\
\hline 59 & 65 & Intestinal tumour & Switzerland, Ticino & $\operatorname{cep} A$ & IBS \\
\hline F59G & 66 & Stool from patient 59 & Switzerland, Ticino & серA & IBS \\
\hline 64 & 70 & $\begin{array}{l}\text { Blood (septicaemia after } \\
\text { sacral decubitus) }\end{array}$ & Switzerland, Ticino & cepA, bft-2 & IBS \\
\hline 120 & 72 & Inguinal abscess & Switzerland, Ticino & серA & IBS \\
\hline F64B & 73 & Stool from patient 64 & Switzerland, Ticino & cep $A$, bft-2 & IBS \\
\hline F120B & 74 & Stool from patient 120 & Switzerland, Ticino & серA & IBS \\
\hline F70A & 80 & Stool from patient 70 & Switzerland, Ticino & серA, bft-1 & IBS \\
\hline ATCC 25285 & & Reference strain & & & $\begin{array}{l}\text { American Type } \\
\text { Culture Collection }\end{array}$ \\
\hline \multicolumn{6}{|l|}{ Division II } \\
\hline 1429 & 82 & Eschar & France, Paris & cfiA-2, IS1186 & M. Sebald \\
\hline BFR271R & 83 & Unknown & France, Paris & cfiA-2, IS1186 & E. Collatz \\
\hline BFR81R & 84 & Unknown & France, Paris & cfiA-2, IS1186 & E. Collatz \\
\hline TAL2480 & 85 & Unknown & USA & cfiA-1, IS942 & [28] \\
\hline TAL3636 & 85 & Unknown & USA & cfiA-1, IS942 & [28] \\
\hline VPI2393 & 86 & Unknown & France, Paris & cfiA-2 & [5] \\
\hline VPI3392 & 87 & Unknown & France, Paris & cfiA-1 & [5] \\
\hline 1297 & 88 & Appendicitis & France, Paris & cfiA-1 & M. Sebald \\
\hline 28794 & 89 & Blood & Norway, Bergen & cfiA-1 & T. Hofstad \\
\hline 127 & 90 & Unknown & Switzerland, Ticino & cfiA-1 & IBS \\
\hline \multicolumn{6}{|l|}{ Outgroup } \\
\hline D3433 & 91 & Lung abscess, hamster & Switzerland, Bern & & J. Nicolet \\
\hline F120C & 93 & Stool from patient 120 & Switzerland, Ticino & & IBS \\
\hline
\end{tabular}

* The ET numbers are those reported in Gutacker et al. [3]

${ }^{\dagger}$ Istituto Cantonale Batteriosierologico, Lugano, Switzerland.

\$Outgroup strains were D3433 (B. uniformis) and F120C (B. ovatus).

\section{DNA sequencing and alignment}

Templates for direct sequencing were prepared by a simple purification step of the PCR products with the QIAquick PCR Purification Kit (Qiagen $\mathrm{GmbH}$, Hilden, Germany) according to the manufacturer's instructions. Cycle sequencing reactions were performed with primers $\operatorname{rec} A-1$ and $g \ln A-1$, respectively, in total volumes of $15 \mu \mathrm{l}$ with an ABI Prism dRhodamine dye terminator Cycle Sequencing Ready Reaction Kit (dRhodamine terminator; Perkin-Elmer Applied Bio- systems) on an ABI Prism 310 Genetic Analyser (Perkin-Elmer Applied Biosystems). When doubtful results or discrepancies were observed, sequences in the opposite directions were obtained with the rec $A-2$ and $g \ln A-2$ primers, respectively. Amplicons of the $c f i A$ gene were sequenced with primers $c f i A-1$ and cfiA-2.

\section{DNA sequence analysis}

The $\operatorname{rec} A, g \ln A$ and $c f i A$ sequences were handled and 
stored with the Lasergene program EditSeq (1994 release; DNAstar, Madison, WI, USA) and aligned separately with Megalign (1994 release, DNAstar). MEGA (Molecular Evolutionary Genetics Analysis 1.01) [22] was used for distance analyses of the $r e c A$ and the $g \ln A$ sequences. Phylogenetic trees were constructed by the neighbour-joining method [23] and the robustness of each node was tested by bootstrap analysis [24], with 500 replications. The numbers of nucleotide substitutions per site were estimated by the Tamura-Nei model [25]. MEGA was also used for estimating percentage base composition and percentage codon usage. Translations to amino acid sequences used the universal genetic code.

\section{Results}

\section{Amplification experiments}

All the $B$. fragilis strains generated the expected $367-$ bp rec $A$ and 780-bp $g \ln A$ amplicons, respectively. The $B$. ovatus and $B$. uniformis isolates produced the recA, but not the $g \ln A$ fragments.

\section{Phylogenetic analysis}

The neighbour-joining method [23] was used to construct phylogenetic trees from both the $\operatorname{rec} A$ and the $\operatorname{gln} A$ sequences (Figs. 1 and 2, respectively). The results obtained with both genes allowed the separation of the

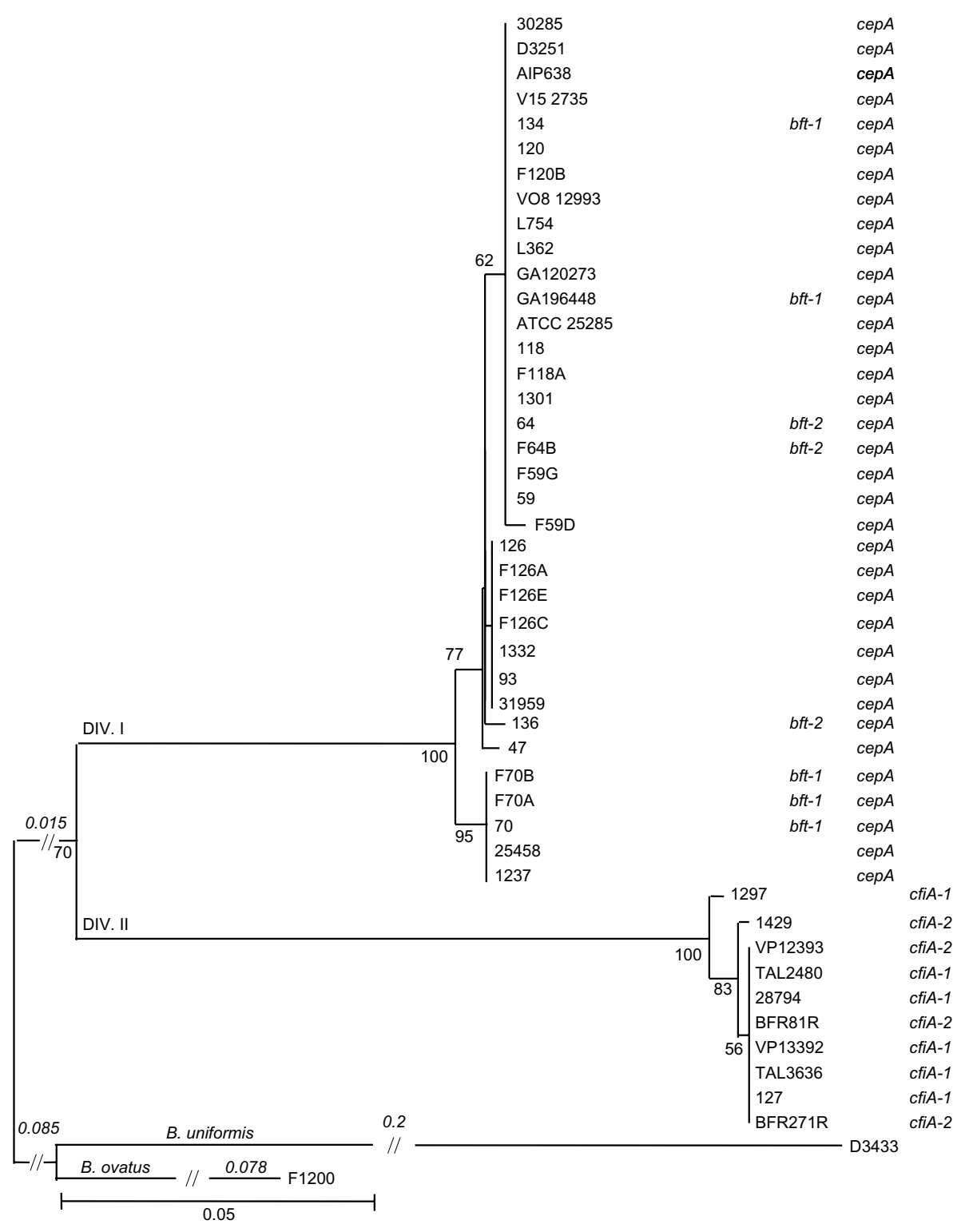

Fig. 1. Neighbour-joining tree based on the sequence alignment of a fragment of $303 \mathrm{bp}$ of the rec $A$ gene, using Tamura-Nei genetic distances. cep $A$ and $c f i A$ are genes encoding antibiotic resistance. $b f t-1$ and $b f t-2$ are two alleles of the enterotoxin encoding gene $b f t$. The clinical and geographical origins of the isolates are summarised in Table 1. Only bootstrap values $>50 \%$ are shown. Genetic distance values are indicated by italic characters where long branches have been cut, for the rest of the dendrogram refer to the bar. 

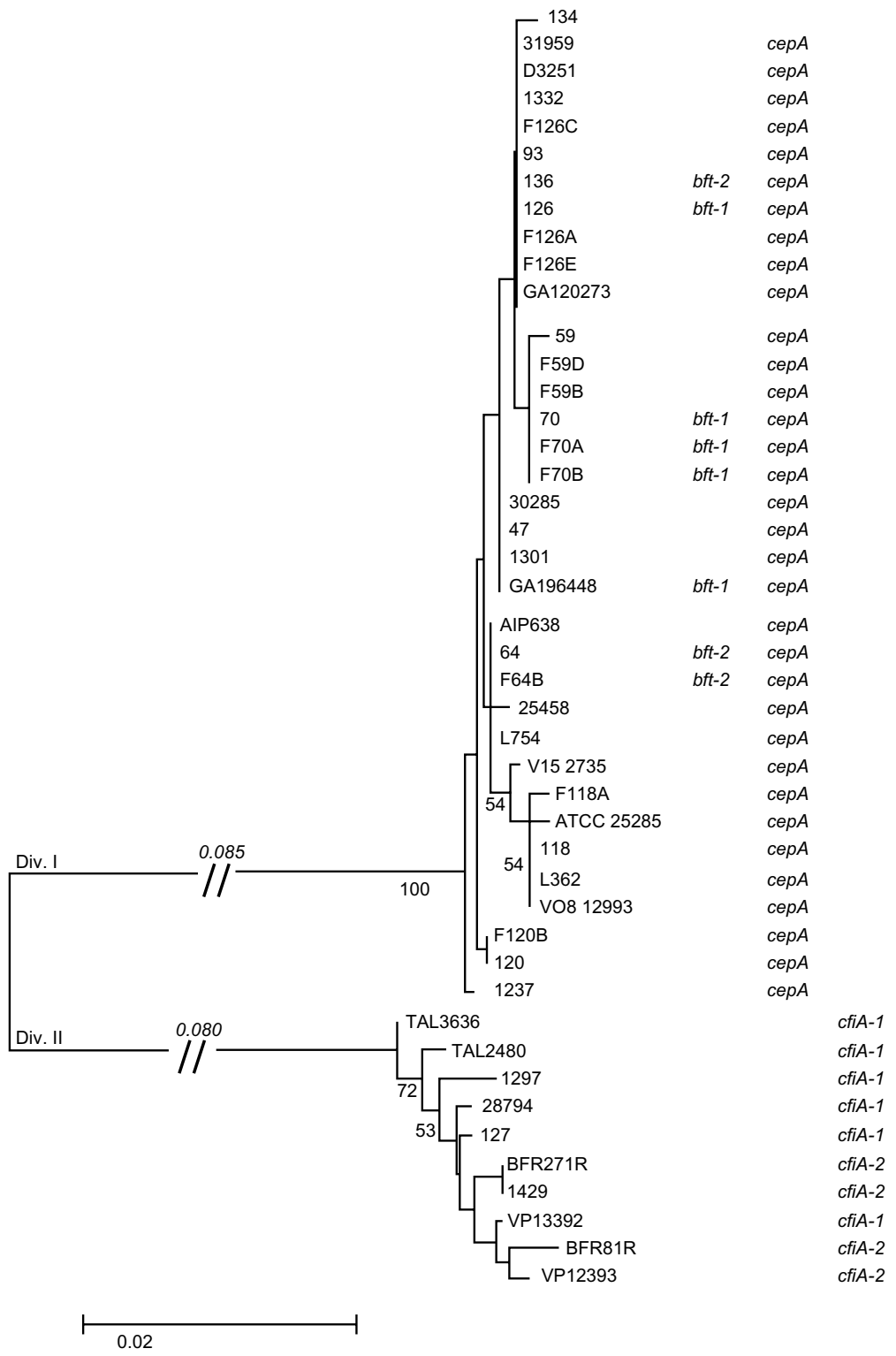

Fig. 2. Neighbour-joining tree based on the sequence alignment of a fragment of $687 \mathrm{bp}$ of the $g \ln A$ gene, using Tamura-Nei genetic distances. cep $A$ and $c f i A$ are genes encoding antibiotic resistance. $b f t-1$ and $b f t-2$ are two alleles of the enterotoxin encoding gene $b f t$. The clinical and geographical origin of the isolates are summarised in Table 1 . Only bootstrap values $>50 \%$ are shown. Genetic distance values are indicated by italic characters where long branches have been cut, for the rest of the dendrogram refer to the bar.

B. fragilis population into two divisions, each associated with a different antibiotic resistance trait $(70 \%$ support in 500 bootstrap replicates in the $\operatorname{rec} A$ tree; as $B$. ovatus and B. uniformis did not generate amplicons, no data were available for the $g \ln A$ gene). Division I comprised 35 isolates. PCR experiments showed that all these isolates carried the серA gene encoding a serine $\beta$-lactamase, but not the cfiA gene encoding a metallo$\beta$-lactamase. Division II comprised 10 isolates carrying cfiA but not cepA. Within the divisions, the low amount of DNA variability of the sequences (see below) prevented phylogenetic evaluation.

Isolates of the same clinical or geographical origin could not be associated with specific clusters. Isolates encoding the $B$. fragilis bft enterotoxin genes (deter- mined by PCR assays [3]) were all in division I, but they were not associated with a particular subgroup within the division.

\section{Genetic diversity within the recA gene of $B$. fragilis}

The average base-pair composition of the 303-bp recA sequences obtained from the 367-bp amplicons was $28.6 \%$ A, 24.2\% T, 22.6\% C and $24.6 \% \mathrm{G}$; 45 of 303 nucleotide sites $(14.8 \%)$ were variable within the $45 \mathrm{~B}$. fragilis strains analysed (Table 2). No insertions or deletions were observed. All nucleotide substitutions were silent; thus, they generated no amino acid replacements. Of 45 variable sites, 40 were directly involved in the subdivision of $B$. fragilis into the two 
Table 2. Number of variable sites in the $r e c A$ gene and genetic distances (range) calculated by the Tamura-Nei model

\begin{tabular}{lccc}
\hline Strains & Variable sites (\%) & $\begin{array}{c}\text { Amino acid } \\
\text { substitutions }\end{array}$ & Genetic distance* \\
\hline Total B. fragilis population & $45(14.8)$ & 0 & $0.1452-0.1633$ \\
Division I & $7(2.3)$ & 0 & $0.0000-0.0167$ \\
Division II & $3(0.9)$ & 0 & $0.0000-0.0100$ \\
B. fragilis- $B$. ovatus & $57(18.8)$ & 8 & $0.1595-0.2263$ \\
B. fragilis- $B$. uniformis & $73(24.1)$ & 8 & $0.2787-0.2940$ \\
B. ovatus- $B$. uniformis & $69(22.8)$ & 12 & 0.2777 \\
\hline
\end{tabular}

* The genetic distance ranges reported are those observed between the isolates of division I and those of division II (total B. fragilis population), within division I or division II only, and between $B$. fragilis and other Bacteroides species, respectively.

divisions described above. Within the divisions themselves only a few nucleotide substitutions occurred: seven within division I and three within division II (Table 2). This generates high genetic distances between the isolates of the two divisions, but not between isolates of the same division. Indeed, Tamura-Nei genetic distance values among $B$. fragilis ranged from 0.1452 to 0.1633 when isolates of division I were compared to those of division II, whereas they ranged from 0 to 0.0167 when comparing isolates within division I and from 0 to 0.0100 when comparing isolates within division II (Table 2). The comparison of the rec $A$ sequences of $B$. fragilis with those of $B$. ovatus and $B$. uniformis is also shown in Table 2 . In all, 25 of 57 nucleotide substitutions observed between $B$. fragilis and $B$. ovatus, and 43 of 73 substitutions observed between $B$. fragilis and B. uniformis were in positions different than the nucleotide substitutions observed between the $B$. fragilis divisions.

\section{Genetic diversity within the glnA gene of $B$. fragilis}

The mean base-pair composition of the 687-bp sequences obtained from the 780-bp amplicons of the $g \ln A$ gene was $28.1 \% \mathrm{~A}, 25.0 \% \mathrm{~T}, 25.9 \% \mathrm{C}$ and $21.0 \%$ $\mathrm{G}$ in both divisions.

For the $g \ln A$ gene, 112 (16.3\%) of 687 nucleotide sites were variable within $B$. fragilis, and again, no insertions or deletions were observed; 96 nucleotide substitutions separated the $B$. fragilis population into the two distinct divisions (Table 3). A low mutation rate was observed within the divisions: 10 nucleotide substitutions within division I and 11 within division
II. The Tamura-Nei genetic distance values ranged from 0.1650 to 0.1865 when isolates of the two divisions were compared with each other, from 0 to 0.0088 when comparing isolates within division I and from 0 to 0.0103 when comparing isolates within division II (Table 3).

Six non-silent variable sites were found. Three of these non-silent sites allowed separation of the $B$. fragilis population into two divisions also at the protein level. However, the substituted amino acids had similar properties: S-105-N (both polar uncharged), V-124-I (both non-polar, hydrophobic) and G-215-S (both polar uncharged).

\section{cfiA sequences of division II}

The base-pair composition of the cfiA amplicons was $21.0 \% \mathrm{~A}, 27.5 \% \mathrm{~T}, 25.2 \% \mathrm{C}$ and $26.3 \% \mathrm{G}$.

The 332-bp sequences obtained from the 353-bp amplicons of the cfiA gene showed seven variable sites. Four nucleotide substitutions (positions 63, 86, 188 and 292) allowed delineation of two groups into the 10 strains carrying the $c f i A$ gene (designated $c f i A-1$ and $c f i A-2$, respectively, Fig. 3). No correlation of the cfiA alleles with imipenem resistance or with particular clusters in the $r e c A$ and $g \ln A$ sequence trees was found (Figs. 1, 2).

\section{Discussion}

The dendrograms generated with both $\operatorname{rec} A$ and $g \ln A$ gene sequence alignments showed the separation of the

Table 3. Number of variable sites in the B. fragilis glnA gene and genetic distances (range) calculated by the Tamura-Nei model

\begin{tabular}{lccc}
\hline Strains & Variable sites (\%) & $\begin{array}{c}\text { Amino acid } \\
\text { substitutions }\end{array}$ & Genetic distance* \\
\hline Total B. fragilis population & $112(16.3)$ & 6 & $0.1650-0.1865$ \\
B. fragilis division I & $10(1.5)$ & 3 & $0.0000-0.0088$ \\
B. fragilis division II & $11(1.6)$ & 2 & $0.0000-0.0103$ \\
\hline
\end{tabular}

* The genetic distance ranges reported are those observed between the isolates of division I and those of division II (total B. fragilis population), within division I or division II only. 


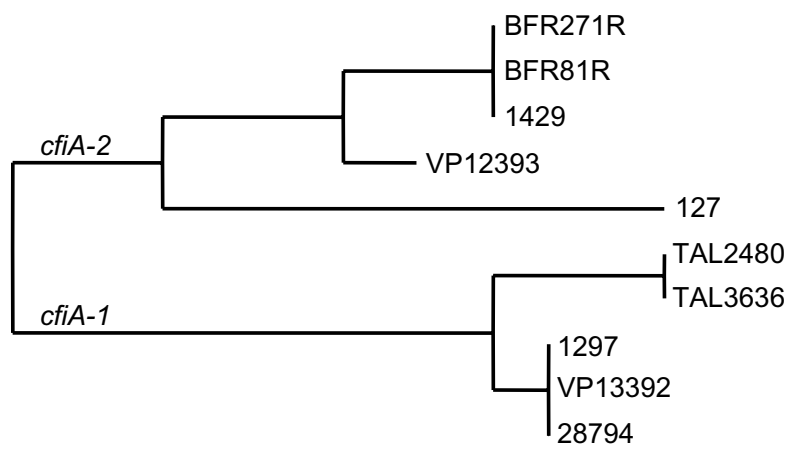

0.002

Fig. 3. Neighbour-joining tree, using Tamura-Nei genetic distances, obtained by the alignment of $333 \mathrm{bp}$ of the $c f i A$ gene. $c f i A-1$ and $c f i A-2$ are two alleles.

B. fragilis population into two robust monophyletic divisions, I and II. The consistency of this subdivision was supported by $70 \%$ bootstrap replicates in the recA tree (Fig. 1). These results are in agreement with those obtained in this laboratory by MLEE [3]: all the strains grouped in division I or II by the enzyme method were found in the corresponding divisions obtained with the sequencing method. Thus, these data support the proposition that sequencing $\operatorname{rec} A$ and $g \ln A$ is reliable for the assessment of bacterial phylogeny, as the evolution of these two genes reflects that of the whole chromosome, at least in B. fragilis.

The $\beta$-lactamase encoding genes cep $A$ and $c f i$ were never found together in the same isolate; moreover, they were associated with distinct genetic divisions cep $A$ was present only in division I and $c f i A$ in division II. This apparent mutual exclusion might be explained by the acquisition of these genes in separate and unique events, generating two distinct lineages, which replaced all the others. These genetic entities have remained successively sufficiently isolated one from the other to avoid horizontal exchanges. Alternatively, a yet unknown gene or genetic element associated with these lineages may inhibit the acquisition of other $\beta$ lactamase-encoding genes. The notion that cep $A$ and $c f i A$ are of different origin is supported by their differing $\mathrm{G}+\mathrm{C}$ mol\% content $(40 \%$ for cepA and $51.5 \%$ for $c f i A$ ) [this work, [26, 27]). However, their genetic localisation has not been clarified yet. A few strains apparently carry the $c f i A$ gene on the chromosome $[27,28]$, although a plasmidic location has also been suggested [29]. No evidence showing an extrachromosomal location of the сер $A$ gene has ever been reported. Further experiments on a larger number of strains are needed to localise cfiA and cepA on the genome of $B$. fragilis and to understand whether and how these genes have been acquired. Interestingly, the $\mathrm{G}+\mathrm{C} \mathrm{mol} \%$ content values determined in this study for $\operatorname{rec} A$ and $g \ln A$ (47.2\% and $46.9 \%$, respectively) are different from the values reported for cepA and $c f i A$
(40\% and $51.5 \%$, respectively), confirming that these genes have been acquired rather recently by lateral transfer.

By sequencing the $c f i A$ gene, this study identified two main alleles, designated $c f i A-1$ and $c f i A-2$ (Table 1 and Figs. 1 and 2). Ruimy et al. [4], using a 729-bp internal fragment of the cfiA sequence as a probe, demonstrated two types of $c f i A$ genes. One type was characterised by a strong hybridisation signal and the other reacted only weakly; this hybridisation difference might have been due to the existence of the two alleles found in the present study.

Although the $c f i A$ gene was present in all 10 isolates of division II, only five $B$. fragilis isolates were phenotypically resistant to imipenem [3]. The expression of the resistance was not correlated to either cfiA allele, nor with a particular cluster within division II. Thus, the expression of the imipenem resistance depends only on the presence of an appropriate insertion sequence element bringing the necessary promoter sequence $[3,6]$.

For both genes, the divergence between the two divisions was consistent (c. $15 \%$ variable sites), whereas the divergence within the divisions ranged from 1 to $2 \%$. Nucleotide variation within the divisions was insufficient to detect phylogenetic relationships at this level, precluding the identification of particular genotypes associated with specific diseases, geographical origin or the production of an enterotoxin (Figs. 1, 2). Nevertheless, enterotoxin-producing $B$. fragilis were found only in division I, as shown previously [3]. This observation supports the hypothesis that horizontal gene transfer between divisions I and II are low, at best.

Due to the genetic distances observed with MLEE (value of 0.7) [3] and to the hybridisation results obtained with a few strains included in the MLEE study (DNA relatedness from 65 to $70 \%$ between the two DNA homology groups and a $\Delta \mathrm{T}_{\mathrm{m}}$ ranging from 7.2 to $\left.9.5^{\circ}[5]\right)$, it can be hypothesised that the two divisions may represent different species. The relatively high genetic distance between the two divisions (0.1452-0.1633 for rec $A$ and $0.1650-0.1865$ for $g \ln A$ ) added to the absence of genetic divergence within each of them (range 0 to 0.0167 ) supports this view. Furthermore, the different codon usage in the $g \ln A$ sequences observed between the divisions (data not shown) gives added weight to this hypothesis. However, in our opinion, the results obtained in this study together with those obtained in this laboratory by MLEE [3] are still insufficient to clarify definitively whether divisions I and II may be considered as two distinct genospecies which have recently diverged, or if they represent two $B$. fragilis groups not yet separated at the species level, but evolving in this direction. 
The GenBank accession nos for the sequences reported in this paper are: AF280701-AF280747 for recA amplicons, AF280638-AF280700 for $g \ln A$ amplicons and AF275830-AF275839 for c fiA amplicons.

We are grateful to J. Bille, E. Collatz, T. Hofstad, N. Kato, J. Meyer, J. Nicolet, A. Pantosti, M. Sebald and R. Zbinden for supplying bacterial strains. This research was supported by grant 31-45914.95 from the Swiss National Science Foundation and by the Helmut Horten Foundation.

\section{References}

1. Franco AA, Cheng RK, Chung G-T, Wu S, Oh H-B, Sears C L. Molecular evolution of the pathogenicity island of enterotoxigenic Bacteroides fragilis strains. J Bacteriol 1999; 181: $6623-6633$.

2. Kato N, Liu C-X, Kato $\mathrm{H}$ et al. A new subtype of the metalloprotease toxin gene and the incidence of the three $b f t$ subtypes among Bacteroides fragilis isolates in Japan. FEMS Microbiol Lett 2000; 182: 171-176.

3. Gutacker M, Valsangiacomo C, Piffaretti J-C. Identification of two genetic groups in Bacteroides fragilis by multilocus enzyme electrophoresis: distribution of antibiotic resistance $(c f i A$, сер $A)$ and enterotoxin $(b f t)$ encoding genes. Microbiology 2000; 146: 1241-1254.

4. Ruimy R, Podglajen I, Breuil J, Christen R, Collatz E. A recent fixation of cfiA genes in a monophyletic cluster of Bacteroides fragilis is correlated with the presence of multiple insertion elements. J Bacteriol 1996; 178: 1914-1918.

5. Johnson JL. Taxonomy of Bacteroides. I. Deoxyribonucleic acid homologies among Bacteroides fragilis and other saccharolytic Bacteroides species. Int J Syst Bacteriol 1978; 28: $245-256$.

6. Podglajen I, Breuil J, Casin I, Collatz E. Genotypic identification of two groups within the species Bacteroides fragilis by ribotyping and by analysis of PCR-generated fragment patterns and insertion sequence content. $J$ Bacteriol 1995; 177: 5270-5275.

7. Yamazoe K, Kato N, Kato H, Tanaka K, Katagiri Y, Watanabe $\mathrm{K}$. Distribution of the cfiA gene among Bacteroides fragilis strains in Japan and relatedness of cfiA to imipenem resistance. Antimicrob Agents Chemother 1999; 43: 2808-2810.

8. Enright MC, Spratt BG. Multilocus sequence typing. Trends Microbiol 1999; 7: 482-487.

9. Maiden MCJ, Bygraves JA, Feil E et al. Multilocus sequence typing: a portable approach to the identification of clones within populations of pathogenic microorganisms. Proc Natl Acad Sci USA 1998; 95: 3140-3145.

10. Reid SD, Herbelin CJ, Bumbaugh AC, Selander RK, Whittam TS. Parallel evolution of virulence in pathogenic Escherichia coli. Nature 2000; 406: 64-67.

11. Karlin S, Weinstock GM, Brendel V. Bacterial classifications derived from recA protein sequence comparisons. J Bacteriol 1995; 177: 6881-6893.

12. Karlin S, Brocchieri L. Evolutionary conservation of recA genes in relation to protein structure and function. $J$ Bacteriol 1996; 178: 1881-1894.

13. Lloyd AT, Sharp PM. Evolution of the recA gene and the molecular phylogeny of bacteria. J Mol Evol 1993; 37: 399-407.

14. Feil E, Zhou J, Maynard-Smith J, Spratt BG. A comparison of the nucleotide sequences of the adk and recA genes of pathogenic and commensal Neisseria species: evidence for extensive interspecies recombination within adk. J Mol Evol 1996; 43: 631-640.

15. Brown JR, Masuchi Y, Robb FT, Doolittle WF. Evolutionary relationships of bacterial and archaeal glutamine synthetase genes. J Mol Evol 1994; 38: 566-576.

16. Kumada Y, Benson DR, Hillemann D et al. Evolution of the glutamine synthetase gene, one of the oldest existing and functioning genes. Proc Natl Acad Sci USA 1993; 90: 3009-3013.

17. Hill RT, Parker JR, Goodman HJK, Jones DT, Woods DR. Molecular analysis of a novel glutamine synthetase of the anaerobe Bacteroides fragilis. J Gen Microbiol 1989; 135: 3271-3279.

18. Goodman HJ, Woods DR. Molecular analysis of the Bacteroides fragilis recA gene. Gene 1990; 94: 77-82.

19. Cooper AJ, Kalinowski AP, Shoemaker NB, Salyers AA. Construction and characterization of a Bacteroides thetaiotaomicron recA mutant: transfer of Bacteroides integrated conjugative elements is RecA independent. J Bacteriol 1997; 179: $6221-6227$.

20. Goodman HJK, Woods DR. Cloning and nucleotide sequence of the Butyrivibrio fibrisolvens gene encoding a type III glutamine synthetase. J Gen Microbiol 1993; 139: 1487-1493.

21. Yamashita Y, Kohno S, Koga H, Tomono K, Kaku M. Detection of Bacteroides fragilis in clinical specimens by PCR. J Clin Microbiol 1994; 32: 679-683.

22. Kumar S, Tamura K, Nei M. MEGA molecular evolutionary genetics analysis, version 1.01, 1993. Pennsylvania State University, University Park, PA 16802.

23. Saitou N, Nei M. The neighbor-joining method: a new method for reconstructing phylogenetic trees. Mol Biol Evol 1987; 4: 406-425.

24. Felsenstein J. Phylogenies from molecular sequences: inference and reliability. Annu Rev Genet 1988; 22: 521-565.

25. Tamura K, Nei M. Estimation of the number of nucleotide substitutions in the control region of mitochondrial DNA in humans and chimpanzees. Mol Biol Evol 1993; 10: $512-526$.

26. Rogers MB, Parker AC, Smith CJ. Cloning and characterization of the endogenous cephalosporinase gene, серA, from Bacteroides fragilis reveals a new subgroup of Ambler class A beta-lactamases. Antimicrob Agents Chemother 1993; 37: 2391-2400.

27. Rasmussen BA, Gluzman Y, Tally FP. Cloning and sequencing of the class B beta-lactamase gene (ccrA) from Bacteroides fragilis TAL3636. Antimicrob Agents Chemother 1990; 34: 1590-1592.

28. Thompson JS, Malamy MH. Sequencing the gene for an imipenem-cefoxitin-hydrolyzing enzyme (cfiA) from Bacteroides fragilis TAL2480 reveals strong similarity between cfiA and Bacillus cereus beta-lactamase II. J Bacteriol 1990; 172: 2584-2593.

29. Bandoh K, Watanabe K, Muto Y, Tanaka Y, Kato N, Ueno K. Conjugal transfer of imipenem resistance in Bacteroides fragilis. J Antibiot 1992; 45: 542-547. 